\title{
Gene transfection of hepatocyte growth factor attenuates cardiac remodeling in the canine heart: A novel gene therapy for cardiomyopathy
}

\author{
Ismayil Ahmet, MD, PhD \\ Yoshiki Sawa, MD \\ Keiji Iwata, MD \\ Hikaru Matsuda, MD
}

From the First Department of Surgery, Osaka University Medical School, Osaka, Japan.

Received for publication Feb 18, 2002; revisions requested April 30, 2002; revisions received May 6, 2002; accepted for publication May 22, 2002.

Address for reprints: Yoshiki Sawa, MD, First Department of Surgery, Osaka University Medical School, 2-2 Yamada-oka, Suita, Osaka 565-0871, Japan (E-mail: sawa@surg1.med.osaka-u.ac.jp).

J Thorac Cardiovasc Surg 2002;124:957-63

Copyright () 2002 by The American Association for Thoracic Surgery

0022-5223/2002 \$35.00+0 12/1/126655

doi: $10.1067 / \mathrm{mtc} .2002 .126655$
Objective: Hepatocyte growth factor, a potent angiogenic agent, is unique in having the effects of antiapoptosis and antifibrosis. In the present study we used the rapid pacing-induced heart failure canine model to investigate the effect of gene transfection of hepatocyte growth factor on the failing heart.

Methods: Four weeks after onset of rapid pacing, either the human hepatocyte growth factor gene $(160 \mu \mathrm{g}$; hepatocyte growth factor group, $\mathrm{n}=7)$ or empty vector (control group, $\mathrm{n}=7$ ) was directly injected into the left ventricular myocardium by means of the hemagglutinating virus of Japan liposome method.

Results: At 4 weeks after gene transfection, the left ventricular global function, assessed by means of pressure-volume loop analysis, was improved in the hepatocyte growth factor group as preload-recruitable stroke work (percentage of baseline: $80 \% \pm 20 \%$ from $38 \% \pm 15 \%$ before gene transfection, $P=.005$ ), whereas it was not changed in the control group $(50 \% \pm 18 \%$ from $50 \% \pm 18 \%)$. Weekly echocardiography showed that this improvement began in the week after gene transfer. The hearts in the hepatocyte growth factor group had a large wall thickness, large myocyte diameter, high capillary density, low fibrotic area fraction, and low density of apoptotic nuclei revealed by means of histologic analysis compared with that in the control group. Myocardial perfusion flow, assessed with color microspheres, was increased in the hepatocyte growth factor group (percentage of baseline: $79 \% \pm 16 \%$ from $48 \% \pm 14 \%, P=.010$ ), whereas it was reduced in the control group $(30 \% \pm 12 \%$ from $45 \% \pm 17 \%)$.

Conclusions: Gene transfection of hepatocyte growth factor promoted angiogenesis, improved perfusion, decreased fibrosis and apoptosis, promoted recovery from myocyte atrophy, and thereby attenuated cardiac remodeling and improved myocardial function in the failing heart. It is a novel gene therapy for human heart failure.

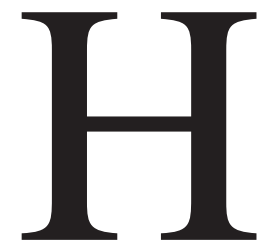
epatocyte growth factor (HGF) is a potent angiogenic agent ${ }^{1}$ possessing mitogenic, motogenic, and morphogenic effects through its own specific receptor, c-Met, in various types of cells, including myocytes. ${ }^{2}$ Recent studies revealed that HGF has effects of antifibrosis and antiapoptosis in the myocardium. ${ }^{3,4}$ Considering the pathologic characteristics of severe heart failure, such as apoptosis-related loss of contractile mass, ${ }^{5}$ progression of fibrosis, ${ }^{6}$ progression of endothelial dysfunction, ${ }^{7}$ and loss of functional capillaries, ${ }^{8}$ HGF might be beneficial in the failing heart by attenuating these remodeling processes.

To test this hypothesis, we used the canine ventricular rapid pacing-induced cardiomyopathy model and performed $H G F$ gene transfer to failing myocardium by 
means of direct intramyocardial administration of hemagglutinating virus of Japan (HVJ) liposomes encoding human $H G F$ cDNA.

\section{Methods}

\section{Animal Model and Experimental Protocol}

Fourteen adult female beagles $(8.0 \pm 1.0 \mathrm{~kg})$ received ventricular rapid pacing for 8 weeks. Care of the animals was in compliance with the "Guide of the Care and Use of Laboratory Animals," prepared by the Institute of Laboratory Animal Resources in Osaka University Medical School, and the "Guide of the Care and Use of Laboratory Animals," published by the National Institute of Health (National Institute of Health publication no. 86-23, revised 1985). Invasive evaluation was done 3 times: (1) at baseline (before onset of rapid pacing); (2) before gene transfection (at 4 weeks after onset of rapid pacing); and (3) after gene transfection (at 4 weeks after gene transfection or 8 weeks after onset of rapid pacing). At each time point, beagles were anesthetized with ketamine $(8 \mathrm{mg} / \mathrm{kg}$ administered intramuscularly) and pentobarbital ( $30 \mathrm{mg} / \mathrm{kg}$ administered intravenously), intubated, and ventilated (Ventilator 710; Siemens-Elema AB, Solna, Sweden). Anesthesia was maintained with inhalation of sevoflurane $(2 \% \mathrm{vol} / \mathrm{vol})$. A small thoracotomy was performed through the fifth intercostal space in the right side for baseline studies and in the left side for studies before and after gene transfection. Implantation of pacemaker was done as follows. Two pacemaker leads were fixed with surgical sutures on the right ventricle free wall surface. A pulse generator (Thera; Medtronic, Eden Prairie, Minn) was placed in a subcutaneous pocket anterior to the right second rib. The pacemaker was programmed and started after the operation at a rate of 240 pulses $/ \mathrm{min}$. A sonomicrometer crystal (WT-20; Crystal Biotech, Hopkinton, Mass) was fixed with surgical sutures on the left ventricular (LV) free wall surface for measurement of regional contractile function. A 7F conductance catheter (Cordis Europe, Roden NA, The Netherlands) and a 5F micromanometer (MPC-500; Millar, Houston, Tex) were inserted into the left ventricle from the apex to measure LV pressure and volume. A flare-tipped catheter was inserted into the left atrium for injection of microspheres. Another catheter was inserted into the left femoral artery for microsphere reference blood sampling. After completion of the evaluation, all 4 catheters were removed; the pericardium and chest were closed. Weekly echocardiography was performed after achievement of light anesthesia with ketamine $(6 \mathrm{mg} / \mathrm{kg}$ administered intramuscularly). The rate of pacemaker stimulation was reduced to $70 \mathrm{pulses} / \mathrm{min}$ at DDD mode before each examination, so that the heart was evaluated at sinus rhythm.

\section{Preparation of Vectors and Gene Transfection}

Human $H G F$ cDNA was inserted into the NotI site of the pUC-SRa expression vector. ${ }^{9}$ HVJ liposome was prepared, as described elsewhere. ${ }^{10}$ Four weeks after onset of rapid pacing, HVJ-HGF liposomes (containing $160 \mu \mathrm{g}$ of $H G F$ gene) or HVJ liposomes in $1 \mathrm{~mL}$ of N-2-hydroxyethylpiperazine-N-2-ethanesulfonic acidbuffered saline solution were introduced into the myocardium by means of direct intramyocardial injection with a 26-gauge needle. Liposomes were injected randomly at 10 sites $(10 \times 0.1 \mathrm{~mL})$ in the LV free wall. Beagles received either the human HGF gene- encoding vector in the HGF group $(\mathrm{n}=7)$ or empty vector in the control group $(n=7)$.

\section{Blood and Tissue HGF Assay}

Venous blood samples were collected daily. One animal in each group was killed at 5 days after gene transfection, and the others were killed at 4 weeks after gene transfection. Five myocardial tissue samples were taken randomly from the LV free wall of each heart, frozen immediately in liquid nitrogen, and stored at $-80^{\circ} \mathrm{C}$ until assay. The levels of human HGF protein in cardiac tissue and plasma were measured by means of enzyme-linked immunosorbent assay with an anti-human HGF monoclonal antibody (Institute of Immunology, Tokyo, Japan), as described previously. ${ }^{11}$ Levels of human $H G F$ mRNA in the myocardium were analyzed by means of reverse transcription-polymerase chain reaction, as described previously. ${ }^{12}$

\section{Measurement of LV Function}

We used a cardiac loop analysis computer system (Signal Processor 1000; NEC, Tokyo, Japan) with a volumetric system (Sigma 5; Leycom, Oegstgeest, the Netherlands) to perform LV pressurevolume loop analysis. Measurements and analyses were performed as previously described. ${ }^{13}$ The preload-recruitable stroke work (PRSW) and the end-systolic pressure-volume relation (ESPVR) were calculated to represent LV global systolic function, and the end-diastolic pressure-volume relation (EDPVR) was calculated to represent LV global diastolic function. Regional myocardial function was measured with the epicardial crystal pulsed-Doppler technique ${ }^{14}$ by using a sonomicrometer crystal. Dobutamine $(20$ $\mu \mathrm{g} \cdot \mathrm{kg}^{-1} \cdot \mathrm{min}^{-1}$ ) was infused intravenously for 10 minutes before recording the data. Thickness fraction (TF) was calculated as previously described. ${ }^{15}$ Echocardiography was performed with an ultrasonograph (SSA-260A; Toshiba Corp, Tokyo, Japan) with a 3.75-MHz transducer. Two-dimensional images of LV and Mmode recordings were obtained for the measurement of posterior wall thickness (PWTh), LV end-diastolic volume (EDV), and ejection fraction $(\mathrm{EF})$.

\section{Evaluation of Regional Myocardial Perfusion}

Regional myocardial perfusion was measured by using the colored microsphere technique. ${ }^{16}$ Microspheres $(15 \mu \mathrm{m}$ in diameter, $3 \times$ $10^{6}$ spheres in each dose) were infused within 20 seconds, and reference blood was withdrawn at a rate of $6 \mathrm{~mL} / \mathrm{min}$. Microspheres in red, yellow, and blue were used for baseline studies and studies before and after gene transfection. Myocardial perfusion was measured at 5 randomly selected myocardial tissue samples in each heart. Perfusion flow was calculated as a percentage of baseline value.

\section{Histologic Evaluation}

The hearts were cut at short axis into several pieces at the end of the experiment. LV wall thickness was directly measured at the midpapillary muscle level at 10 sites in each heart. From frozen tissue samples, myocardium was cut into $5-\mu \mathrm{m}$-thick slices and stained with the following, according to the manufacturer's manual. First, a rabbit polyclonal antibody against human factor VIIIassociated antigen (DAKO Corporation, Carpinteria, Calif), which is a marker for endothelial cells, was used for vessel staining. 


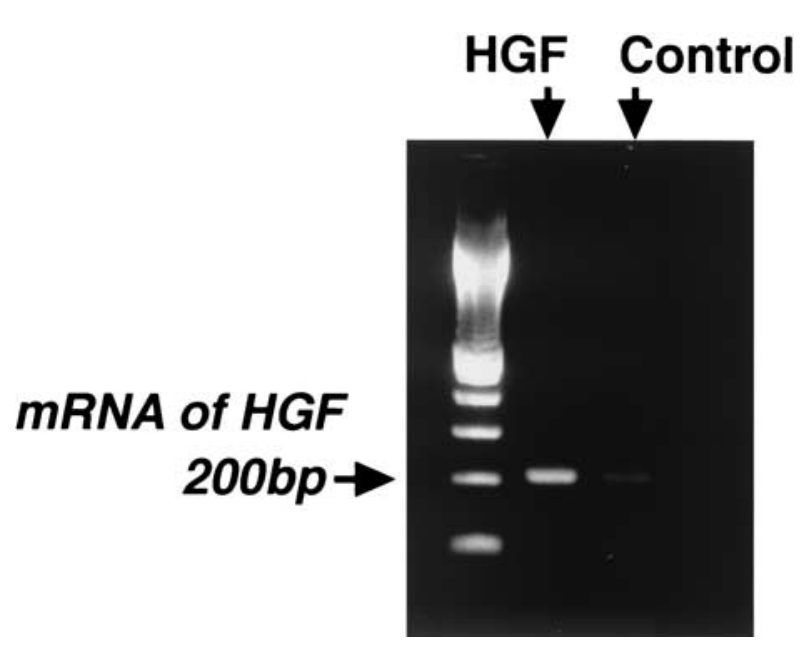

Figure 1. HGF mRNA expression in the LV myocardium at 5 days after gene transfection by means of reverse transcription-polymerase chain reaction of human HGF. A high level of HGF mRNA was observed in the heart receiving the HGF gene vector but not in the heart receiving the empty vector (control). Molecular size markers are shown in the left margin.

Second, an in situ apoptosis detection kit (Apoptag) was used in the terminal deoxynucleotidyl transferase mediated dUTP nickend labeling (TUNEL) for apoptosis. Third, elastica Van-Gieson staining of collagen was used to examine the fibrosis. Fourth, hematoxylin and eosin staining was performed. Computer (MacScope v 2.5.1; Mitani Corp, Tokyo, Japan) appraisal of pathology (vascular density, percentage of amount of TUNEL-positive nuclei, fibrotic area fraction, and myocyte diameter) was performed on 10 randomly chosen optical fields $\left(0.56 \mathrm{~mm}^{2}\right)$ of each heart. A pathologist who was blind to treatment carried out histologic evaluation.

\section{Statistical Analysis}

All values are expressed as means \pm SD. Comparisons (PWTh, $\mathrm{EDV}$, and EF) were performed by using 1-way analysis of variance, followed by the Bonferroni least-significant-difference test. Others (cardiac functional indices and histologic data) were compared by using the Student $t$ test.

\section{Results}

\section{Efficiency of Gene Transfection}

Protein and mRNA of human $H G F$ were detected in the LV myocardium at 5 days after gene transfection in the HGF group only ( $0.17 \mathrm{ng}$ of protein in $1 \mathrm{~g}$ of tissue wet weight), whereas they were not detected in the control group (Figure 1). Neither was detected in either group at 4 weeks after gene transfection. There was no detectable $(<0.01 \mathrm{ng})$ human HGF in blood throughout the experiment.

\section{HGF Promotes Recovery of Myocytes From Atrophy} The PWTh, determined on the basis of echocardiography, was significantly increased in the HGF group $(6.6 \pm 1.1$ $\mathrm{mm}$ from $3.9 \pm 1.0 \mathrm{~mm}$ before gene transfection, $P=.001$ ),
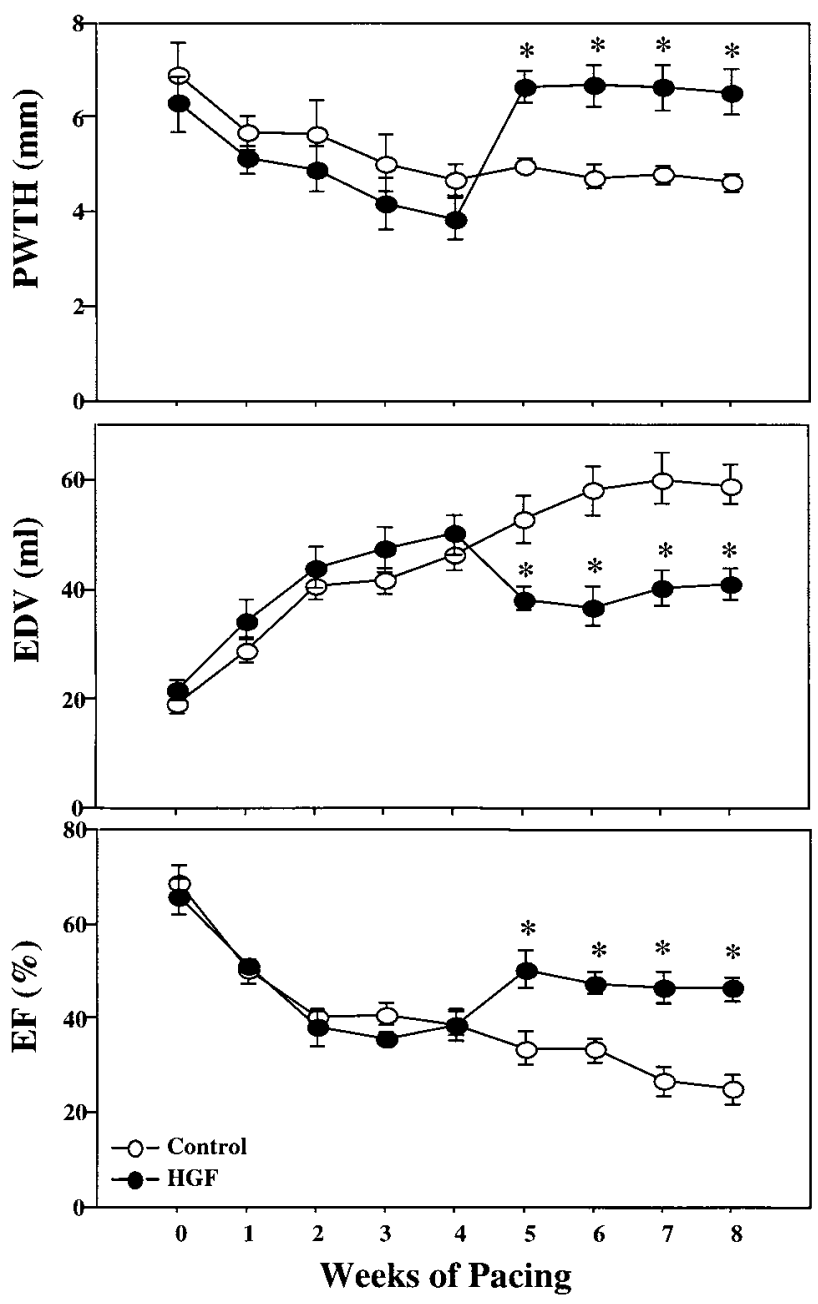

Figure 2. Echocardiographic findings. The PWTh and EF were improved, and EDV was reduced soon after transfection in the HGF group. Data are expressed as means \pm SEM. ${ }^{*} \boldsymbol{P}<.05$ versus the control group.

whereas it was not changed in the control group $(4.7 \pm 0.5$ $\mathrm{mm}$ from $4.7 \pm 0.8 \mathrm{~mm}$ before gene transfection, $P=.826$ ). EDV was slightly reduced in the HGF group (41.4 \pm 7.3 $\mathrm{mL}$ from $50.4 \pm 9.1 \mathrm{~mL}$ before gene transfection, $P=$ .088 ), whereas it was significantly increased in the control group $(59.4 \pm 9.1 \mathrm{~mL}$ from $46.9 \pm 7.7 \mathrm{~mL}$ before gene transfection, $P=.027$, Figure 2 ). The gross anatomy showed that the LV wall thickness, by means of direct measurement, was significantly higher in the HGF group $(9.8 \pm 2.1 \mathrm{~mm}, P=.020)$ than in the control group $(7.1 \pm$ $0.7 \mathrm{~mm}$ ). The myocyte diameter was significantly greater in the HGF group (33 $\pm 4 \mu \mathrm{m}, P=.0001)$ than in the control group ( $23 \pm 4 \mu \mathrm{m}$; Figure $3, A$ ).

HGF Promotes Angiogenesis and Perfusion

The capillary density was significantly higher in the HGF group $\left(1667 \pm 531 / \mathrm{mm}^{2}, P=.011\right)$ than in the control 


\section{HGF}

A
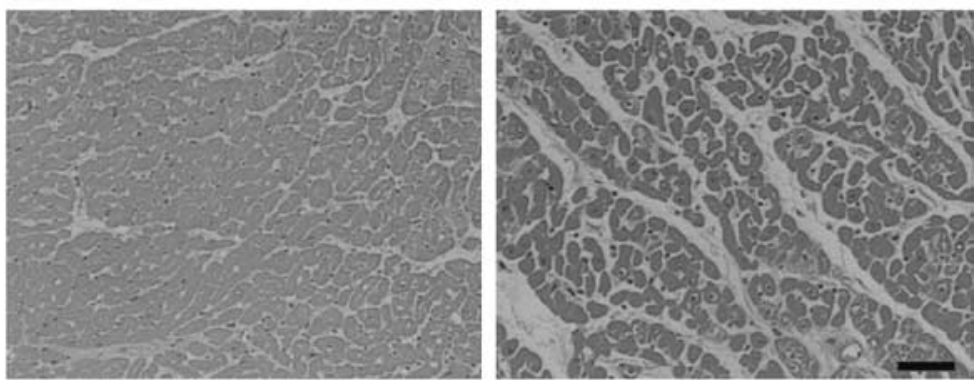

B
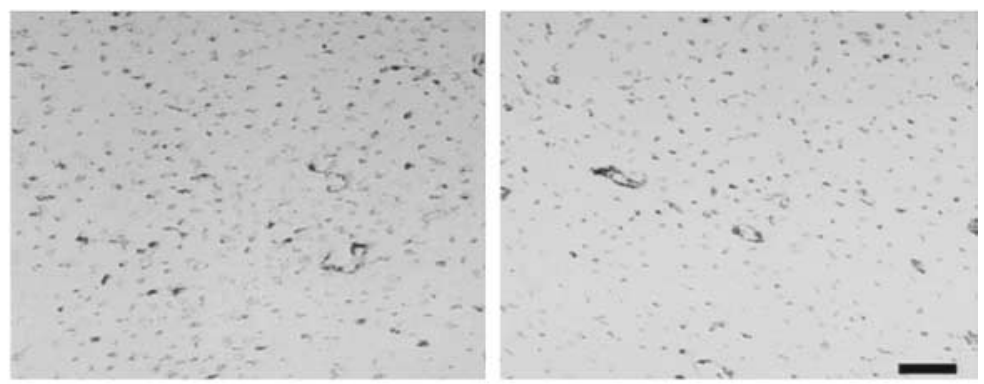

C
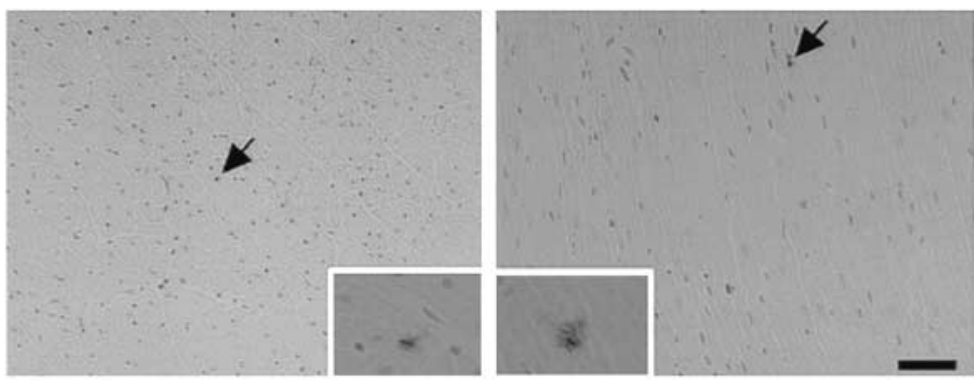

D
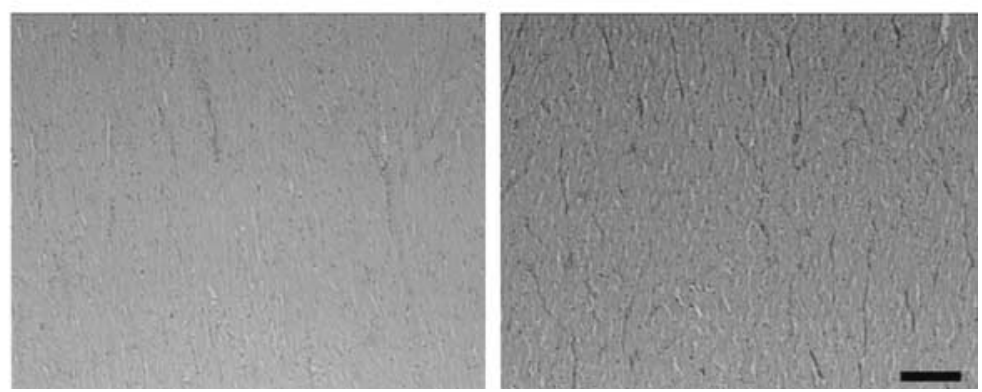

Figure 3. Histopathology of LV myocardium. A, Hematoxylin and eosin-stained tissue sections (bar $=50 \mu \mathrm{m}$ ). The myocyte diameter is higher in the HGF group than in the control group. B, Sections were stained with antibody against factor VIII and counterstained with eosin $(b a r=50 \mu \mathrm{m})$. The vessel density is higher in the HGF group than in the control group. C, Sections were stained with TUNEL and counterstained with eosin (bar $=50 \mu \mathrm{m}$ ). High magnification shows TUNEL-positive myocytes (arrow). The number of TUNEL-positive cells is lower in the HGF group than in the control group. D, Sections with Van Gieson staining of collagen and eosin counterstaining (bar = $100 \mu \mathrm{m})$. The fibrotic area is smaller in the HGF group than in the control group.

group $\left(811 \pm 360 / \mathrm{mm}^{2}\right.$; Figure 3, B). Perfusion flow (percentage of baseline) was significantly improved in the HGF group $(78.9 \% \pm 15.5 \%$ from $47.8 \% \pm 13.7 \%$ before gene transfection, $P=.010)$, whereas it was slightly reduced in the control group $(30.7 \% \pm 12.6 \%$ from $44.9 \% \pm 16.9 \%$ before gene transfection, $P=.128$ ). 
TABLE 1. Indices of LV function

\begin{tabular}{|c|c|c|c|c|c|c|c|c|c|}
\hline & \multicolumn{3}{|c|}{ Control } & \multirow[b]{2}{*}{$P$ value* } & \multicolumn{3}{|c|}{ HGF } & \multirow[b]{2}{*}{$P$ value* } & \multirow[b]{2}{*}{$P$ value } \\
\hline & Baseline & Pregene & Postgene & & Baseline & Pregene & Postgene & & \\
\hline \multirow{2}{*}{\multicolumn{10}{|c|}{$\begin{array}{l}\text { Systolic function } \\
\text { PRSW }\end{array}$}} \\
\hline & & & & & & & & & \\
\hline Slope (1000 erg/mL) & $83.2 \pm 5.6$ & $40.9 \pm 13.7$ & $41.9 \pm 15.8$ & .908 & $81.2 \pm 5.9$ & $30.3 \pm 9.7$ & $64.9 \pm 17.0$ & .004 & .045 \\
\hline$\%$ of baseline & & $49.6 \pm 18.1$ & $49.9 \pm 17.7$ & .974 & & $37.8 \pm 14.6$ & $80.0 \pm 20.0$ & .005 & .026 \\
\hline \multicolumn{10}{|l|}{ ESPVR } \\
\hline Slope (mm Hg/mL) & $9.7 \pm 1.9$ & $4.9 \pm 2.4$ & $6.3 \pm 1.7$ & .260 & $9.5 \pm 1.7$ & $4.5 \pm 2.5$ & $9.2 \pm 1.2$ & .004 & .010 \\
\hline$\%$ of baseline & & $49.6 \pm 18.6$ & $66.4 \pm 16.9$ & .132 & & $45.4 \pm 20.3$ & $98.5 \pm 16.6$ & .001 & .011 \\
\hline \multicolumn{10}{|l|}{$\begin{array}{l}\text { Diastolic function } \\
\text { EDPVR }\end{array}$} \\
\hline Slope $\left(10^{-2} \mathrm{~mm} \mathrm{Hg} / \mathrm{mL}\right)$ & $83.4 \pm 12.5$ & $143.0 \pm 52.4$ & $211.5 \pm 47.4$ & .038 & $87.7 \pm 11.7$ & $147.6 \pm 45.2$ & $116.4 \pm 22.7$ & .204 & .002 \\
\hline$\%$ of baseline & & $168.1 \pm 42.6$ & $252.9 \pm 44.4$ & .007 & & $169.6 \pm 52.0$ & $131.8 \pm 9.5$ & .148 & .0002 \\
\hline \multicolumn{10}{|l|}{$\begin{array}{l}\text { Regional function } \\
\text { TF }(\%)\end{array}$} \\
\hline Rest & $18.0 \pm 2.2$ & $7.1 \pm 1.8$ & $6.3 \pm 1.8$ & .515 & $18.0 \pm 2.2$ & $6.2 \pm 2.8$ & $10.2 \pm 3.2$ & .029 & .032 \\
\hline Stress & $25.0 \pm 8.5$ & $6.8 \pm 2.7$ & $7.7 \pm 1.9$ & .521 & $27.3 \pm 6.0$ & $7.5 \pm 2.9$ & $13.6 \pm 3.5$ & .017 & .005 \\
\hline
\end{tabular}

Data are expressed as mean \pm SD. Pregene, Before gene transfection; Postgene, after gene transfection.

*Postgene versus Pregene within group.

†Postgene versus Postgene between groups.

\section{HGF Inhibits Apoptosis and Fibrosis}

The percentage of TUNEL-positive myocytes was significantly lower in the HGF group $(0.4 \% \pm 0.4 \%, P=.049)$ than in the control group $(1.5 \% \pm 1.0 \%$; Figure $3, C)$. The percentage area of fibrosis was also significantly less in the HGF group $(0.6 \% \pm 0.2 \%, P=.0002)$ than in the control group $(2.0 \% \pm 0.6 \%$; Figure $3, D)$.

\section{HGF Improves LV Contractile Function}

The EF, determined on the basis of echocardiography, was slightly increased in the HGF group $(46.4 \% \pm 5.6 \%$ from $38.8 \% \pm 7.9 \%$ before gene transfection, $P=.083$ ), whereas it was significantly reduced in the control group $(25.3 \% \pm$ $7.5 \%$ from $39.0 \% \pm 6.3 \%$ before gene transfection, $P=$ .006 , Figure 2). Table 1 shows the LV systolic and diastolic functions before and after gene transfection. A good recovery of PRSW and ESPVR was observed in the HGF group, with the values significantly better than those before gene transfection. Values after gene transfection of EDPVR, a measurement of LV diastolic function, were significantly better in the HGF group than in the control group. The TF, either at rest or under dobutamine stress, was significantly improved in the HGF group, whereas it was not changed in the control group.

\section{Discussion}

The present study has demonstrated that $H G F$ gene transfection improves the LV function in a canine model of rapid pacing-induced cardiomyopathy. This improvement was associated with promoted myocardial recovery from atrophy, increased myocardial collateral-vessel development and perfusion, and reduced myocardial fibrosis and apoptosis.

Considering the gene therapy in a future clinical trial, only the patients with symptoms of severe heart failure can be candidates. Therefore this study was designed to perform the gene transfer of $H G F$ at 4 weeks after onset of rapid pacing, when those hearts showed a marked pathologic change of cardiomyopathy with significant deterioration of cardiac function similar to the characteristics of cardiomyopathy.

As opposed to conventional therapies that focus on alleviating the symptoms of heart failure, the concept for the use of HGF is to attenuate pathologic remodeling of heart failure. By promoting angiogenesis, attenuating apoptosis and fibrosis, and promoting the myocyte recovery from atrophy in the failing myocardium, this new concept is an attempt to preserve and increase the contractile mass, reshape the ventricular geometry, improve myocardial perfusion, and change interstitial collagen composition. These methods have been proved to be functionally advantageous.

We used 3 independent methods to measure cardiac function. EF from echocardiography, TF from epicardial crystal pulse-Doppler technique, and PRSW, ESPVR, and EDPVR from pressure-volume loop analysis indicated the same result: $H G F$ gene transfection can improve cardiac function in the failing heart. PRSW, ESPVR, and EDPVR have been proposed as a load-independent index of contractile function ${ }^{17}$ and were used as the gold standard of LV function. The crystal was fixed on the LV surface and measured at the same place throughout the experiment. As a result, our conclusion is correct and reliable. 
The findings on LV wall thickness, volume, and myocyte diameter indicated that HGF promotes myocardial recovery from atrophy and reshaped the ventricular geometry in the canine cardiomyopathy model. The underlying mechanism of this effect is probably that through c-Met, a transmembrane tyrosine kinase, HGF activates the Ras-Raf-MEKERK signaling pathway, which is implicated in myocardial hypertrophy. ${ }^{18,19}$ Because of the danger of myocardial biopsy, we did not have any histologic information of the heart before gene transfection. However, on the basis of histologic findings from our previous canine model studies, we concluded that myocyte diameter was recovered to a normal level from atrophy. The absence of HGF at 4 weeks after gene transfection indicated that the preservation of this recovery seems not to depend on HGF supply for at least several weeks. The future of this recovery is still unknown.

The myocardial vasculature is an obligatory determinant of the ventricular remodeling. ${ }^{20}$ Coronary perfusion is decreased in failing myocardium as a result of fibrosis and structural changes in the capillary network. ${ }^{8}$ The findings in capillary density and myocardial perfusion indicated that HGF promotes angiogenesis in the failing myocardium. The most important point is that those new capillaries were functional to increase myocardial perfusion. Concerning the regional perfusion flow, previous experiments showed that there is tremendous animal-to-animal variability at all levels of the myocardium. We found a large variation of actual perfusion flow (approximately $0.6-3.9 \mathrm{~mL} \cdot \mathrm{min}^{-1} \cdot \mathrm{g}^{-1}$ ) in different parts of same heart and the same parts of different hearts. Only the rates of change are equal in most parts of the heart.

Myocyte loss occurs through apoptosis in chronic heart failure. HGF has an antiapoptotic effect, likely through the activation of the phosphatidylinositol-3-OH kinase pathway. ${ }^{4,21}$ The findings in the TUNEL staining of apoptosis indicated that HGF prevented the myocardial apoptosis and thereby preserved the LV contractile mass. This conclusion was based on careful identification of every apoptotic cell in the examined myocardial sections. Because apoptotic cells are degraded within 1 to 2 weeks, the apoptotic cell numbers would be lower in the week after $H G F$ gene transfection.

The mechanism underlying the antifibrotic effect of HGF is probably related to the activation of matrix metalloproteinases, the inhibition of collagen formation, and the inhibition of transforming growth factor $\beta$ secretion. ${ }^{22}$ The findings in the fibrotic area fraction indicated that HGF prevented the remodeling on myocardial collagen. Less fibrosis in the myocardium is beneficial in improving the contractile function and angiogenesis of failing myocardium.

Previous studies reported the beneficial effects of insulin-like growth factor or growth hormone therapy in animal models of heart failure. ${ }^{23,24}$ However, their effects in pa- tients with heart failure are still controversial. ${ }^{25}$ Promotion of myocardial hypertrophy and attenuation of apoptosis only by insulin-like growth factor or growth hormone therapy or promotion of angiogenesis only by vascular endothelial growth factor or fibroblast growth factor therapy are likely not to be sufficient to attenuate cardiac remodeling in heart failure. Therefore HGF might be the most promising agent for heart failure therapy among the growth factor family.

This study, for the first time, showed the effectiveness of $H G F$ gene therapy in heart failure by functional and pathologic evidence but leaves several unresolved issues. First, because of the limitations of experimental space and financing, there is no mechanism study. We expect this will be clarified in the near future in small animal models. Second, because of a lack of measurement techniques for canine HGF, changes and roles of endogenous HGF in this model are not clear. Third, the long-term outcome of those effects of HGF is not clear. Fourth, this dose came from a previous gene dose/HGF protein expression ratio study in canine heart by means of direct injection. There was no doseresponse study in this model. Other alternative routes will be studied in the near future.

Because of some similarities between this canine experimental model and human cardiomyopathy, ${ }^{26}$ the results of this study provide preliminary evidence that $H G F$ gene transfection might provide a therapeutic method for treatment of human heart failure. If future studies using gene therapy with HGF in patients with end-stage heart disease demonstrate a beneficial effect on mortality and morbidity, this new therapeutic approach might become an attractive alternative to cardiac transplantation or became a bridge to transplantation in these patients.

\section{References}

1. Aoki M, Morishita R, Taniyama Y, Kida I, Moriguchi A, Matsumoto $\mathrm{K}$, et al. Angiogenesis induced by hepatocyte growth factor in noninfarcted myocardium and infarcted myocardium: up-regulation of essential transcription factor for angiogenesis, ets. Gene Ther. 2000; 7:417-27.

2. Matsumoto K, Nakamura T. Emerging multipotent aspects of hepatocyte growth factor. J Biochem. 1996;119:591-600.

3. Taniyama Y, Morishita R, Nakagami H, Moriguchi A, Sakonjo H, Kim S, et al. Potential contribution of a novel antifibrotic factor, hepatocyte growth factor, to prevention of myocardial fibrosis by angiotensin II blockade in cardiomyopathic hamsters. Circulation. 2000;102:246-52.

4. Kitta K, Day RM, Ikeda T, Suzuki YJ. Hepatocyte growth factor protects cardiac myocytes against oxidative stress-induced apoptosis. Free Radic Biol Med. 2001;31:902-10.

5. Narula J, Haider N, Virmani R, DiSalvo TG, Kolodgie FD, Hajjar RJ, et al. Apoptosis in myocytes in end-stage heart failure. $N$ Engl J Med. 1996;335:1182-9.

6. Pauschinger M, Knopf D, Petschauer S, Doerner A, Poller W, Schwimmbeck PL, et al. Dilated cardiomyopathy is associated with significant changes in collagen type I/III ratio. Circulation. 1999;99: 2750-6.

7. Treasure CB, Alexander RW. The dysfunctional endothelium in heart failure. J Am Coll Cardiol. 1993;22:A129-34. 
8. Parodi O, De Maria R, Oltrona L, Testa R, Sambuceti G, Roghi A, et al. Myocardial blood flow distribution in patients with ischemic heart disease or dilated cardiomyopathy undergoing heart transplant. Circulation. 1993;88:509-22.

9. Seki T, Hagiya M, Shimonishi M, Nakamura T, Shimizu S. Organization of human hepatocyte growth factor-encoding gene. Gene. 1991; 102:213-9.

10. Kaneda Y. A Laboratory Handbook: Virus (sendai virus envelops)mediated gene transfer. In: Celis JE, editor. Cell biology. New York: Academic Press; 1994. p. 3, 50-57.

11. Yamada A, Matsumoto K, Iwanari H, Sekiguchi K, Kawata S, Matsuzawa Y, et al. Rapid and sensitive enzyme-linked immunosorbent assay for measurement of HGF in rat and human tissues. Biomed Res. 1995; $16: 105-14$.

12. Ueda H, Sawa Y, Matsumoto K, Kitagawa-Sakakida S, Kawahira Y, Nakamura T, et al. Gene transfection of hepatocyte growth factor attenuates reperfusion injury in the heart. Ann Thorac Surg. 1999;67: 1726-31.

13. Ahmet I, Fukushima N, Sawa Y, Masai T, Kadoba K, Kagisaki K, et al. The effect of a new ultra-short-acting beta-adrenergic blocker, ONO-1101, on cardiac function during and after cardiopulmonary bypass. Surg Today. 1999;29:248-54.

14. Zhu WX, Myers ML, Hartley CJ, Roberts R, Bolli R. Validation of a single crystal for measurement of transmural and epicardial thickening. Am J Physiol. 1986;251:H1045-55.

15. Calnon DA, Glover DK, Beller GA, Vanzetto G, Smith WH, Watson $\mathrm{DD}$, et al. Effects of dobutamine stress on myocardial blood flow, ${ }^{99 \mathrm{~m}} \mathrm{Tc}$ sestamibi uptake, and systolic wall thickening in the presence of coronary artery stenoses: implications for dobutamine stress testing. Circulation. 1997;96:2353-60.

16. Kowallik P, Schulz R, Guth BD, Schade A, Paffhausen W, Gross R, et al. Measurement of regional myocardial blood flow with multiple colored microspheres. Circulation. 1991;83:974-82.

17. Glower DD, Spratt JA, Snow ND, Kabas JS, Davis JW, Olsen CO, et al. Linearity of the Frank-Starling relationship in the intact heart: the concept of preload recruitable stroke work. Circulation. 1985;71:9941009.

18. Nakamura T, Mizuno S, Matsumoto K, Sawa Y, Matsuda H, Nakamura T. Myocardial protection from ischemia/reperfusion injury by endogenous and exogenous HGF. J Clin Invest. 2000;106:1511-9.

19. Akiyama Y, Ashizawa N, Seto S, Ohtsuru A, Kuroda H, Ito M, et al. Involvement of receptor-type tyrosine kinase gene families in cardiac hypertrophy. J Hypertens. 1999;17:1329-37.

20. Lewis BS, Gotsman MS. Relation between coronary artery size and left ventricular wall mass. Br Heart J. 1973;35:1150-3.

21. Fan S, Ma YX, Wang JA, Yuan RQ, Meng Q, Cao Y, et al. The cytokine hepatocyte growth factor/scatter factor inhibits apoptosis and enhances DNA repair by a common mechanism involving signaling through phosphatidyl inositol 3' kinase. Oncogene. 2000;19:2212-23.

22. Ueki T, Kaneda Y, Tsutsui H, Nakanishi K, Sawa Y, Morishita R, et al. Hepatocyte growth factor gene therapy of liver cirrhosis in rats. Nat Med. 1999;5:226-30.

23. Lee WL, Chen JW, Ting CT, Ishiwata T, Lin SJ, Korc M, et al. Insulin-like growth factor I improves cardiovascular function and suppresses apoptosis of cardiomyocytes in dilated cardiomyopathy. Endocrinology. 1999;140:4831-40.

24. King MK, Gay DM, Pan LC, McElmurray JH 3rd, Hendrick JW, Pirie $\mathrm{C}$, et al. Treatment with a growth hormone secretagogue in a model of developing heart failure: effects on ventricular and myocyte function. Circulation. 2001;103:308-13.

25. Smit JW, Janssen YJ, Lamb HJ, van der Wall EE, Stokkel MP, Viergever E, et al. Six months of recombinant human GH therapy in patients with ischemic cardiac failure does not influence left ventricular function and mass. J Clin Endocrinol Metab. 2001;86: 4638-43.

26. Wilson JR, Douglas P, Hickey WF, Lanoce V, Ferraro N, Muhammad A, et al. Experimental congestive heart failure produced by rapid ventricular pacing in the dog: cardiac effects. Circulation. 1987;75: 857-67.

\section{Bound volumes available to subscribers}

Bound volumes of The Journal of Thoracic and Cardiovascular Surgery are available to subscribers (only) for the 2002 issues from the Publisher, at a cost of $\$ 134.00$ for domestic, $\$ 165.85$ for Canadian, and $\$ 155.00$ for international subscribers for Vol 123 (January-June) and Vol 124 (July-December). Shipping charges are included. Each bound volume contains a subject and author index and all advertising is removed. The binding is durable buckram with the Journal name, volume number, and year stamped in gold on the spine. Payment must accompany all orders. Contact Mosby, Subscription Customer Service, 6277 Sea Harbor Dr, Orlando, FL 32887, USA; phone 800-654-2452 or 407-345-4000.

Subscriptions must be in force to qualify. Bound volumes are not available in place of a regular Journal subscription. 